\title{
Analysis of company operating feasibility using Energy Productivity Ratio (EPR)
}

\author{
Nurhayati Sembiring ${ }^{1, *}$, Novita Sari Br Purba ${ }^{2}$ \\ ${ }^{1}$ Lecturer Department of Industrial Engineering, Faculty of Engineering, University Sumatera Utara, Medan, Indonesia \\ ${ }^{2}$ Student Department of Industrial Engineering, Faculty of Engineering, University Sumatera Utara, Medan - Indonesia
}

\begin{abstract}
This research is conducted in a company engaged in the manufacture of pesticides. The company has never measured it's energy productivity. The company is only based on production targets and financial benefits achieved each year. One method that can be used in productivity measurement and operational feasibility is Energy Productivity Ratio (EPR). EPR is expressed as the ratio of energy output to the energy input. The feasibility of the company's operation can be seen from the energy productivity value. The purpose of research conducted to 1) Measure the level of energy productivity 2) Measuring the feasibility of the company's operations 3) Identify the factors that influence the value of energy productivity ratio (EPR) and 4) Provide proposed steps to increase energy productivity. EPR is made by collecting data on material requirements, power requirements, machine and equipment data and the number of products produced. After doing the calculation of energy input and energy output, the final step is to calculate the value of Energy Productivity Ratio (EPR). By this research we know the company is feasible to operate because the value of $E P R>1$, although it must be repaired to increase the value.
\end{abstract}

Keywords: Energy Productivity Ratio (EPR);productivity energy; ratio;input;outpu

\section{Introduction}

Every company that want to survive has to improve its performance in competitive competition. Better products and achieved high productivity must be a final goal. Company performance must continually measured as an assesment in order to compete with other companies.[1].

It should be known how is the company's current performance. By calculating the productivity we could assess the performance of a company. One defenition of productivity is the ratio between the value an activity generates for the value of all the inputs used in doing the activity. Productivity is also has a means that management analyze and encourage production efficiency as well as to check how the company utilizes its input (resources) in producing output (products). It is known that so important make productivity measurement of company performance and also feasibility of the company's operations, i.e production function, cost function and profit function [2].

The company that this research conducted produces herbicides and insecticides, such as DMA, Dursban, Garlon, Nurelle, and Thopshot. It has never measured company's energy ratio productivity. The company's performance is only based on production targets and financial benefits achieved each year. One method that can be applied in productivity measurement and operational feasibility is Energy Productivity Ratio (EPR). By this method we analyzed the ratio of energy output to the energy input. From the energy productivity value of the company, we could know feasibility of the company's operation. By using Energy Productivity Ratio (EPR) it is easier to detect the energy productivity and feasibility of the company's operations. Finally the management could arrange the energy needs that will be apllied in production planning to achieve high profits as well. By reducing energy use, it means maximize potential reduction of carbon emissions. Other environmental issues related to carbon emission occur from energy use especially from heavy electricity and firewood use.

From this reason, it is necessary to do research related to Energy Productivity Ratio (EPR) and what factors influence the value of the EPR.

\section{Literature review}

In Indonesia, manufacturing industry influences Gross Domestic Product. GDP is an important indicator of economic condition. Manufacturing industry sector has big contribution to economic growth and also absorbs many workers [3]. Hence manufacturing industry has strong relationship with energy consumption. Some research has been done about energy consumption.

\footnotetext{
* Corresponding author: nurhayatipandia68@usu.ac.id
} 
Economic growth deeply influenced by how the energy input allocated. There is always a connection between energy consumption and economic growth. Some research show that productivity could be improved by analizwd the energy that used. Economic prosperity also influenced by energy consumption [4].

By comparing output with input, that means compare the results achieved with the overall resources used, we get the score of productivity. As it known, productivity has two dimensions. The first dimension is the achievement of targets about time, quality and quantity. This dimension is known as the effectiveness. The second is done by comparing inputs with the realization of the work. This dimension is known as the efficiency.

From another references, defenition of effectiveness in a production process is the level of goal achievement. By measured effectiveness, we easily explains how much the output obtained in accordance with the targets that have been made by the company. Yet from another references, the interpretation of efficiency is the amount of use of input used in a production process to get the output.

Effectiveness and Efficiency have strong differences. Effectiveness measure the amount of company target that can be reached in getting the output. Where efficiency is used to determine the amount of use of resources in a manufacturing process $[3,4,5,6,7]$.

Energy is needed to do work (effort). Energy can be changed from one form to another, meaning that energy can not be destroyed. Energy is an important factor of development of industrial growth. By reducing energy consumption could be influenced to energy productivity. Energy prices also has limited role in the growth of energy productivity. The rise in the price of energy carriers, have impact on productivity of the industry $[8,9]$.

In a production process, material be used to produce a product. The materials used in the energy process are materials that need energy. By dividing the total cost of materials with the price of fuel energy we could know the energy of materials, then calculate it with the value of heat values of these fuels.

An electrical energy is the final energy required for electrical appliances, i.e lighting, heating, to drive motors, to reactivate a mechanical device to produce another form of energy. [10,11].

Besides that, depreciation energy is one indirect energy factor. The indirect energy associated with the manufacture of the tool can be determined by calculating the value of 1) Depreciation energy from the production of a device 2) Depreciation of the purchase price of the tool. [12]

The ratio of the energy input derived from the electrical energy, the total energy of the materials, the compliance used in the production process compared to the energy output and the depreciation of the machine is known as The Energy Productivity Ratio (EPR). EPR method can be used to determine the value of energy productivity[4,5].

The formula for determining the energy input of the materials is as follows:

$$
\text { Input energy materials }=\frac{A}{B} x \text { C............(1) }
$$

$$
\begin{aligned}
& A=\text { Total material price }(\mathrm{Rp}) \\
& B=\text { Fuel Prices }(\mathrm{Rp}) \\
& C=\text { Calorific value of fuel }(\mathrm{MJ} / \mathrm{Kg})
\end{aligned}
$$

The value of electrical energy input can be obtained by calculating the power needs of the company and then converted to MJ units. The formula for calculating the energy input of the converted material is as follows:

Input electrical energy $=$ Electrical power $(k w h) x$ 3,6 MJ...(2)

The result of calculation of material energy input, electrical energy input and energy input of machine and equipment depreciation then summed to become energy input value. Next, look for energy output values. The formula for calculating the required energy output is as follows:

$$
\begin{aligned}
& \text { Output energy materials }=\frac{D}{B} x C \ldots \ldots \ldots \\
& A= \text { Total material product }(\mathrm{Rp}) \\
& B=\text { Fuel Prices }(\mathrm{Rp}) \\
& C=\text { Calorific value of fuel }(\mathrm{MJ} / \mathrm{Kg})
\end{aligned}
$$

The energy value of the productivity ratio (EPR) can be calculated after the energy input value and the energy output value have been obtained. The formula of energy productivity ratio (EPR) is as follows:

$$
E P R=\frac{\text { Output Energy }(O E)}{\text { Input Energy }(I E)}
$$

The energy value of productivity ratio (EPR) greater than 1 , indicates that the product production process can be continued or declared feasible. Whereas if the energy ratio is $1<1$ then the production of the product is declared not worth continuing. New fuel needs to be sought to reduce losses and use energy sources declared as energy-deficient energy sources and needs to be revisied $[5,6]$.

\section{Methodology}

The research was conducted at North Sumatera. The type of research conducted in this study is descriptive research. Descriptive research is a type of research used to describe the systematic, factual and accurate about the facts and the properties of an object or population to be studied. The results of this study aims to determine the energy productivity and feasibility of the company's operations.

The object of research observed is the production section. This research was conducted to measure and analyze energy productivity. 
The purpose of this research is as follows: 1. Measuring the level of the company's energy product. 2. Measuring the feasibility of the company's operations.

3. Identify the factors that affect the value of energy productivityratio(EPR).

4.Providing proposed steps to increase energy productivity.

Based on the data obtained, the calculation of energy input and energy output, so it can be calculated value of Energy Productivity Ratio (EPR) company $[5,6]$.

\section{Result and discussion}

EPR calculation can be done if it has obtained the value of energy input and energy output. Therefore, energy value and energy output should be calculated first.

\subsection{Energy Input Calculation}

Energy input calculation is the sum of the required energy input materials. The required energy inputs are the energy input of the material, the input of the required power energy and the energy input of the machine and equipment depreciation.

\subsubsection{Energy Material Input Calculation}

The calculation of energy input of the required materials is done using the material price data required per month during 2014-2017. Input energy of materials required in 2014-2017 can be seen in Table 1.

Table 1. Energy Material Input

\begin{tabular}{clcccc}
\hline \multirow{2}{*}{ No } & \multirow{2}{*}{ Month } & \multicolumn{4}{c}{ Year } \\
\cline { 3 - 6 } & & $\mathbf{2 0 1 4}(\mathbf{M J})$ & $\mathbf{2 0 1 5}(\mathbf{M J})$ & $\mathbf{2 0 1 6}(\mathbf{M J})$ & $\mathbf{2 0 1 7}(\mathbf{M J})$ \\
\hline 1 & January & 1.312 .221 .711 & 1.222 .223 .002 & 1.260 .886 .207 & 1.479 .817 .831 \\
2 & February & 1.890 .930 .561 & 1.531 .100 .729 & 1.502 .170 .330 & 1.495 .032 .757 \\
3 & March & 1.891 .292 .102 & 1.536 .620 .174 & 1.496 .545 .816 & 1.484 .871 .176 \\
4 & April & 1.829 .444 .440 & 1.548 .543 .949 & 1.489 .116 .935 & 1.184 .433 .442 \\
5 & May & 1.643 .683 .965 & 1.417 .200 .995 & 1.507 .677 .427 & 1.478 .105 .590 \\
6 & June & 1.875 .720 .076 & 1.505 .887 .850 & 1.482 .581 .466 & 1.258 .429 .325 \\
7 & July & 1.246 .901 .850 & 1.224 .146 .744 & 1.252 .080 .522 & 1.472 .202 .840 \\
8 & August & 1.870 .433 .422 & 1.570 .733 .694 & 1.483 .669 .668 & 1.467 .730 .664 \\
9 & September & 1.936 .995 .139 & 1.520 .860 .533 & 1.466 .354 .729 & 1.467 .866 .328 \\
10 & October & 1.920 .127 .568 & 1.522 .717 .385 & 1.463 .446 .505 & 1.467 .445 .360 \\
11 & November & 1.860 .187 .079 & 1.535 .960 .386 & 1.474 .966 .647 & 1.466 .147 .529 \\
12 & December & 1.212 .850 .663 & 1.196 .003 .042 & 1.278 .954 .258 & 1.251 .520 .703 \\
\hline \multicolumn{2}{c}{ Total } & $\mathbf{2 0 , 4 9 0 , 7 8 8 , 5 7 5}$ & $\mathbf{1 7 . 3 3 1 . 9 9 8 . 4 8 1}$ & $\mathbf{1 7 . 1 5 8 . 4 5 0 . 5 1 0}$ & $\mathbf{1 6 . 9 7 3 . 6 0 3 . 5 4 5}$ \\
\hline
\end{tabular}

\subsubsection{Electrical Energy Input Calculation}

The calculation of the required electrical energy input is done using the required electrical power data per month during 2014-2017. Input of electrical energy required in 2014-2017 can be seen in Table 2 .
Table 2. Electrical Energy Input

\begin{tabular}{clcccc}
\hline \multirow{2}{*}{ No } & \multirow{2}{*}{ Month } & \multicolumn{4}{c}{ Year } \\
\cline { 3 - 6 } & & $\mathbf{2 0 1 4}(\mathbf{M J})$ & $\mathbf{2 0 1 5}(\mathbf{M J})$ & $\mathbf{2 0 1 6}(\mathbf{M J})$ & $\mathbf{2 0 1 7}(\mathbf{M J})$ \\
\hline 1 & January & 682.140 & 722.266 & 722.266 & 762.392 \\
2 & February & 802.518 & 802.518 & 802.518 & 802.518 \\
3 & March & 1.003 .147 & 882.770 & 882.770 & 842.644 \\
4 & April & 977.270 & 860.003 & 834.256 & 795.167 \\
5 & May & 722.266 & 802.518 & 842.644 & 842.644 \\
6 & June & 842.644 & 882.770 & 882.770 & 722.266 \\
7 & July & 682.140 & 722.266 & 722.266 & 882.770 \\
8 & August & 842.644 & 882.770 & 882.770 & 882.770 \\
9 & September & 882.770 & 882.770 & 882.770 & 762.392 \\
10 & October & 922.895 & 922.895 & 882.770 & 922.895 \\
11 & November & 802.518 & 842.644 & 882.770 & 882.770 \\
12 & December & 682.140 & 722.266 & 762.392 & 762.392 \\
\hline \multicolumn{2}{r}{ Total } & $\mathbf{9 . 8 4 5 . 0 9 2}$ & $\mathbf{9 . 9 2 8 . 4 5 4}$ & $\mathbf{9 . 9 8 2 . 9 5 8}$ & $\mathbf{9 . 8 6 3 . 6 1 8}$ \\
\hline
\end{tabular}

\subsubsection{Energy Depreciation Machine and Equipment Input Calculation}

Energy input calculations depreciate the required machinery and equipment using machine and equipment data required per month during 2014-2017. Calculation of machine and equipment depreciation is done using the straight-line method. Input energy depreciation machines and equipment required in 2014-2017 can be seen in Table3.

Table 3. Depreciation Machine and Equipment Energy Input

\begin{tabular}{clcccc}
\hline \multirow{2}{*}{ No } & \multirow{2}{*}{ Month } & \multicolumn{4}{c}{ Year| } \\
\cline { 3 - 6 } & & $\mathbf{2 0 1 4}(\mathbf{M J})$ & $\mathbf{2 0 1 5}(\mathbf{M J})$ & $\mathbf{2 0 1 6}(\mathbf{M J})$ & $\mathbf{2 0 1 7}(\mathbf{M J})$ \\
\hline 1 & January & $73.779,54$ & $73.779,54$ & $73.779,54$ & $73.779,54$ \\
2 & February & $73.779,54$ & $73.779,54$ & $73.779,54$ & $73.779,54$ \\
3 & March & $73.779,54$ & $73.779,54$ & $73.779,54$ & $73.779,54$ \\
4 & April & $73.779,54$ & $73.779,54$ & $73.779,54$ & $73.779,54$ \\
5 & May & $73.779,54$ & $73.779,54$ & $73.779,54$ & $73.779,54$ \\
6 & June & $73.779,54$ & $73.779,54$ & $73.779,54$ & $73.779,54$ \\
7 & July & $73.779,54$ & $73.779,54$ & $73.779,54$ & $73.779,54$ \\
8 & August & $73.779,54$ & $73.779,54$ & $73.779,54$ & $73.779,54$ \\
9 & September & $73.779,54$ & $73.779,54$ & $73.779,54$ & $73.779,54$ \\
10 & October & $73.779,54$ & $73.779,54$ & $73.779,54$ & $73.779,54$ \\
11 & November & $73.779,54$ & $73.779,54$ & $73.779,54$ & $73.779,54$ \\
12 & December & $73.779,54$ & $73.779,54$ & $73.779,54$ & $73.779,54$ \\
\hline & Total & $\mathbf{8 8 2 . 7 1 4 , 4 8}$ & $\mathbf{8 8 2 . 7 1 4 , 4 3}$ & $\mathbf{8 8 2 . 7 1 4 , 4 8}$ & $\mathbf{8 8 2 . 7 1 4 , 4 8}$ \\
\hline
\end{tabular}

\subsection{Energy Output Calculation}

The calculation of output energy produced is done using product price data generated per month. Ouput energy produced in 2014-2017 can be seen in Table 4.

Table 4. Energy Output

\begin{tabular}{clcrcr}
\hline \multirow{2}{*}{ No } & \multirow{2}{*}{ Month } & \multicolumn{4}{c}{ Year| } \\
\cline { 2 - 6 } & & $\mathbf{2 0 1 4}(\mathbf{M J})$ & $\mathbf{2 0 1 5}(\mathbf{M J})$ & $\mathbf{2 0 1 6}(\mathbf{M J})$ & \multicolumn{1}{c}{$\mathbf{2 0 1 7}(\mathbf{M J})$} \\
\hline 1 & January & 3.057 .004 .457 & 2.036 .312 .605 & 1.371 .538 .335 & 2.227 .388 .191 \\
2 & February & 1.904 .438 .388 & 1.443 .784 .719 & 1.375 .863 .523 & 1.390 .284 .927 \\
3 & March & 1.230 .511 .849 & 1.964 .382 .741 & 1.091 .388 .268 & 2.096 .386 .942 \\
4 & April & 2.830 .383 .115 & 760.352 .511 & 1.092 .039 .426 & 1.577 .218 .184 \\
5 & May & 1.735 .848 .405 & 1.293 .141 .932 & 1.767 .634 .767 & 2.085 .714 .271 \\
6 & June & 1.412 .179 .474 & 1.370 .614 .280 & 2.105 .096 .460 & 1.319 .353 .713 \\
7 & July & 1.815 .706 .533 & 1.281 .797 .126 & 2.742 .852 .993 & 1.416 .515 .924 \\
8 & August & 3.915 .876 .157 & 1.471 .193 .205 & 2.097 .258 .068 & 1.906 .388 .140 \\
9 & September & 2.492 .325 .527 & 1.401 .422 .269 & 1.064 .827 .114 & 1.503 .119 .850 \\
10 & October & 885.184 .089 & 1.557 .153 .052 & 1.291 .752 .277 & 1.733 .092 .440 \\
11 & November & 1.305 .087 .996 & 3.128 .242 .749 & 1.492 .737 .406 & 874.242 .110 \\
12 & December & 833.642 .795 & 1.988 .641 .247 & 1.323 .726 .964 & 835.951 .168 \\
\hline \multicolumn{2}{l}{ Total } & $\mathbf{2 3 . 4 1 8 . 1 8 8 . 7 8 5}$ & $\mathbf{1 9 . 6 9 7 . 0 3 8 . 4 3 5}$ & $\mathbf{1 8 . 8 1 6 . 7 1 5 . 5 9 9}$ & $\mathbf{1 8 . 9 6 5 . 6 5 5 . 8 6 0}$ \\
\hline
\end{tabular}




\subsection{Energy Productivity Ratio (EPR) Calculation}

Energy Productivity Ratio (EPR) calculation is done using energy output data divided by energy input. Energy Productivity Ratio (EPR) in 2014-2017 can be seen in Table 5.

Table 5. Energy Productivity Ratio

\begin{tabular}{clcccc}
\hline \multirow{2}{*}{ No } & \multirow{2}{*}{ Month } & \multicolumn{4}{c}{ Year } \\
\cline { 3 - 6 } & & $\mathbf{2 0 1 4}$ & $\mathbf{2 0 1 5}$ & $\mathbf{2 0 1 6}$ & $\mathbf{2 0 1 7}$ \\
\hline 1 & January & 2,33 & 1,66 & 1,09 & 1,50 \\
2 & February & 1,01 & 0,94 & 0,92 & 0,93 \\
3 & March & 0,65 & 1,28 & 0,73 & 1,41 \\
4 & April & 1,55 & 0,49 & 0,73 & 1,33 \\
5 & May & 1,06 & 0,91 & 1,17 & 1,41 \\
6 & June & 0,75 & 0,91 & 1,42 & 1,05 \\
7 & July & 1,46 & 1,05 & 2,19 & 0,96 \\
8 & August & 2,09 & 0,94 & 1,41 & 1,30 \\
9 & September & 1,29 & 0,92 & 0,73 & 1,02 \\
10 & October & 0,46 & 1,02 & 0,88 & 1,18 \\
11 & November & 0,70 & 2,04 & 1,01 & 0,60 \\
12 & December & 0,69 & 1,66 & 1,03 & 0,67 \\
\hline & Total & $\mathbf{1 4}$ & $\mathbf{1 4}$ & $\mathbf{1 3}$ & $\mathbf{1 3}$ \\
\hline
\end{tabular}

\subsection{Discussion}

The energy input is the sum of the energy input of the required material, the required energy energy input and the energy input of the machine and equipment depreciation.

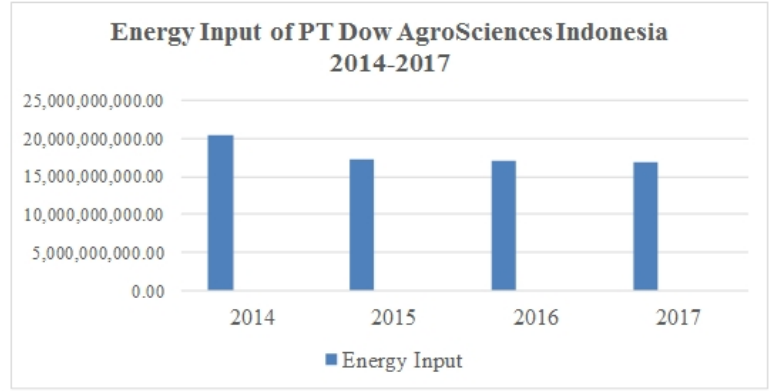

Fig. 2. Energy Input

Based on the data of energy input in 2014-2017, the decrease of energy input from 2014 to 2017 is 20,501,516,381,54 MJ, 17,342,809,649,40 MJ, $17,169,316,182,75 \mathrm{MJ}$ and 16,984,394,876,77 MJ. This decrease of energy input is influenced by material needs, electrical energy and depreciation of machinery and equipment used .

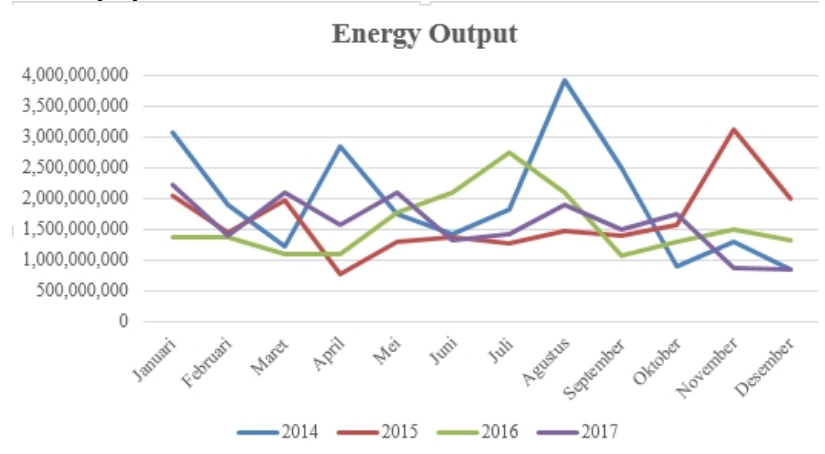

Fig. 3. Energy Output
Energy output in the year 2014-2017 is the highest in November 2014 ie 3.128.242.749 MJ and the lowest energy output occurred in April 2015 ie 760.352.511 MJ. The highest average energy output occurs in 2014. This is influenced by the amount of pesticide produced and the type of pesticide produced in that year is higher than the amount of pesticide produced and the type of pesticide produced in subsequent years, so that the energy output generated in 2014 is higher than in previous years.

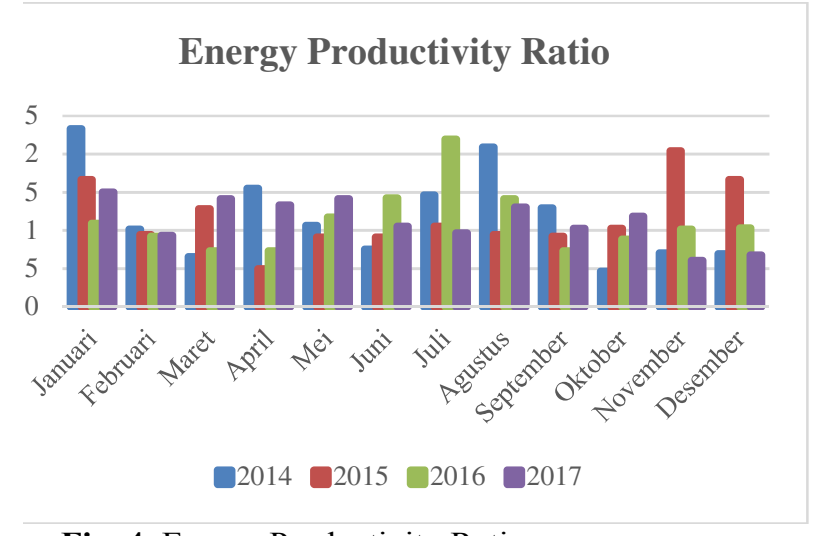

Fig. 4. Energy Productivity Ratio

Based on the table and graph of energy productivity ratio (EPR) can be seen that the value of EPR fluctuated up and down which means that the company's performance can be said not yet stable. However, the average energy productivity ratio (EPR) of firms in 2014, 2015, 2016 and 2017 is 1.17, 1.15, 1.11, and 1.11. From the average value of the company is feasible to operate because the value of EPR $>1$, although it must be repaired to increase the value of EPR so there is no longer the value of EPR below 1 .

Increasing the value of energy productivity ratio (EPR) can be done by considering the factors that affect the value, namely energy input and energy output. The following data for energy input and energy output in 2014 in 2014 will be used to look at the factors affecting the value of the energy productivity ratio (EPR).

The ups and downs of EPR values are influenced by energy inputs in the form of energy inputs of materials and electricity requirements, as well as energy output. Differences in energy input needs of materials is influenced by the amount of raw materials and needed auxiliary materials and variations in the size of products to be produced, whereas the required electrical energy input is affected by the number of working days per month.

\section{Conclusion and future work}

1. From the results of the discussion that has been done then taken the following conclusions: Input of energy in 2014-2017, there is a decrease of energy input from 2014 to 2017 which is 
20,501,516,381,54 MJ, 17,342,809,649,40 MJ, $17,169,316,182,75 \mathrm{MJ}$ and 16,984,394,876,77 MJ. Energy output in the year 2014-2017 is the highest in November 2014 ie 3.128.242.749 MJ and the lowest energy input occurred in April 2015 ie 760.352.511 MJ. The highest energy productivity ratio (EPR) in the year 2014-2017 was the highest in January 2014 at 2.33 and the lowest energy productivity ratio (EPR) occurred in November 2017 of 0.60.

2. The average energy productivity ratio (EPR) of firms in 2014, 2015, 2016 and 2017 is 1.17, 1.15, 1.11 , and 1.11. From the average value of the company is feasible to operate because the value of EPR $>1$, although it must be repaired to increase the value of EPR so there is no longer the value of EPR below 1 .

3. Factors affecting the value of energy productivity ratio (EPR) are energy inputs consisting of energy input materials, electrical energy inputs and energy inputs depreciation of machinery and equipment, as well as the energy output that is influenced by the amount of product produced and the price of the resulting product.

The advice given to the company is:

1. Companies should make production planning with regard to product type and product selling price to be produced every month.

2. Companies must be careful in choosing suppliers to order materials in the production process because the quality of raw materials have an important role in achieving good output.

3. The company should plan the maintenance schedule of the machine, not only do the repair when the machine is damaged. The company should also use the production machine as efficiently as possible in order to reduce energy use so that energy productivity can be improved.

\section{Acknowlegments}

Authors wish to thank to the company that this research conducted.

\section{References}

1. A. Frefer, etc. Productivity Analysis of The General Electric Company of Libya, American Journal of Management Science and Engineering, 2(6), 192-198 (2017)
2. T. Nababan, Measuring Efficiency of Fuel Oil Usage in PT PLN: A Short-Run Analysis, Advances in Economics, Business and Management Research, 46 (2017)

3. W. Aji, etc. Thermoeconomical Productivity Analysis in Manufacturing Sector, Journal of Physics: Conferemce Series (2017)

4. M.S Rahman, etc. The Interdependent Relationship Between Social Productivity and Disaggregated Energy Consumption in Malaysia: Markov witching Approach, Renewable and Sustainable Energy Review, 67, (2017)

5. B. Haryanto, etc. Study in Energy Productivity Ratio (EPR) at Palm Kernel Oil Processing Factory: Case Study on PT-X at Sumatera Utara Plantation, Material Science and Engineering 309 (2018)

6. B. Haryanto, etc. Utilization of The Sand from Mount Eruption as Material for Planting Media, Advances in Economics, Business and Management Research, 46 (2017)

7. T. Mahmood. Long Run Relationship Between Energy Effeviency and Economic Growth in Pakistan: Time Series Data Analysis, Forman Journal of Economic Studies, 13, 105-120 (2017)

8. C.I.P. Martinez, Estimating and Analysis Energy Effeciency in German and Colombian Manufacturing Industries Using DEA and Data Panel Analysis. Part II: Non-Energy Intensive Sectors, Energy Sources (2016)

9. N. Ryan. Energy Productivity and Energy Demand: Experimental Evidence from Undian Manufacturing Plants (2018)

10. S.H. Zimsar, Enhancers of The Energy Effeciency in Tea Processing Industry, Energy Equipment and System, 6 (2018)

11. A. Seal, etc. Productivity, Energy Use Effeciency and Economics of Organnic Scented Rice Cultivation in Sub-Humid Agroecosystem, Asean Research Journal of Agriculture (2017)

12. D. Amedegbe-Doe, etc. Determination of Depreciation of Consytuction Plant Using The Straight Line Method, International Journal of Advance Engineering Research and Technology, 5 (2017) 